\title{
Enteritis eosinofílica idiopática en una vaca lechera de Antioquia
}

\section{Idiopathic eosinophilic enteritis in a dairy cow from Antioquia}

\author{
María Ramírez R, ${ }^{2 *}$ M.Sc, Berardo Rodríguez, ${ }^{2}$ Ph.D, Nicolás Ramírez V, ${ }^{1}$ M.Sc. \\ Universidad de Antioquia, Facultad de Ciencias Agrarias. Medellín, Colombia. ${ }^{1}$ Grupo de investigación \\ Centauro, ${ }^{2}$ Grupo de investigación Quirón. * Correspondencia: mariacon_1@hotmail.com
}

Recibido: Septiembre de 2010; Aceptado: Noviembre de 2011.

\begin{abstract}
RESUMEN
La Enteritis Eosinofílica Idiopática (EEI) es una enfermedad de causa desconocida, reportada en los humanos y en varias especies animales. En el bovino se ha aceptado desde 1998 como una entidad poco común, con escasos reportes a nivel mundial. En este estudio se documenta una vaca que presentó inflamación intestinal de curso crónico, diagnosticada como EEI con base en el análisis de los hallazgos clínicos, histopatológicos y la exclusión de otras enfermedades intestinales. Esta comunicación constituye el primer reporte en Colombia de esta condición en el bovino y tiene como objetivo describir los hallazgos clínicos y anatomopatológicos encontrados y discutir sus posibles causas y mecanismos de enfermedad. Debido a que no se identificaron agentes infecciosos en el caso estudiado y a que la vaca presentó concomitantemente neoplasias, se postula como mecanismo de enfermedad más probable, el síndrome hipereosinofilia paraneoplásica.
\end{abstract}

Palabras clave: Ganado, hipersensibilidad, intestinos, patología (Fuente:CAB).

\begin{abstract}
Idiopathic Eosinophilic enteritis (IEE) is a disease of unknown cause reported in humans and various animal species. In cattle it has been accepted since 1998 as a rare entity, with few reports worldwide. This study documents the process of a cow that showed intestinal inflammation of chronic characteristics, diagnosed with IEE based on clinical and histopathological analysis as well as the exclusion of other intestinal diseases. This account is based on the first report of this condition in Colombian cattle and aims to describe clinical and anatomopathologic findings and the discussion of its possible causes and mechanisms of the disease. Because no infectious agents were identified in the case studied, and the fact hat the cow presented related neoplasms, the most probable mechanism of disease presented is the, paraneoplastic hypereosinophilia syndrome.
\end{abstract}

Key words: Cattle, hypersensitivity, intestines, pathology (Source:CAB). 


\section{INTRODUCCIÓN}

La enteritis o inflamación del intestino se presenta en diferentes etapas productivas en los bovinos (1), causa cuadros clínicos agudos o crónicos que dependen en su evolución y en sus manifestaciones clínicas del tipo de agente etiológico involucrado, de las vías de infección y de factores asociados como edad, estado nutricional, enfermedades concomitantes e inmunosupresión. Los efectos de la enteritis son mediados por varios mecanismos que interactúan entre sí y dependen de la evolución de la enfermedad (2).

Una de las formas de presentación de la enteritis crónica es la denominada Enteritis Eosinofílica Idiopática (EEI). Esta es una enfermedad emergente que se ha identificado en el hombre (3), en equinos, en caninos (4), en ovejas (5), en gatos, en primates no humanos (6) y en bovinos (7). Sus manifestaciones clínicas más frecuentes son diarrea crónica, pérdida de peso, pobre crecimiento y ascitis $(8,9)$.

Las causas y mecanismos de la EEI en las diferentes especies no están bien identificados; no obstante, se proponen varias asociadas entre ellas, alergia alimentaria o medicamentosa, hipersensibilidad en respuesta a parásitos, hongos, cuerpos extraños, plantas y neoplasias $(10,11)$.

La técnica hasta el presente para el diagnóstico de esta condición es la histopatología y los hallazgos microscópicos característicos son inflamación intestinal con infiltración predominante por eosinófilos $(3,10)$. Aunque la EEI se reporta desde 1937 en el humano (3), en el bovino esta apenas se realizó en 1998 (7), luego de este reporte la EEI, ha sido aceptada como una enfermedad de los bovinos por otros autores $(8,12,1)$. Debido a su reciente publicación y a lo poco común de la enfermedad se desconoce su prevalencia y su impacto económico en la producción bovina.

En Antioquia (Colombia) y particularmente en vacas lecheras, son comunes las enfermedades diarreicas de curso crónico, sin embargo, la EEI en esta especie hasta donde se conoce no se ha reportado en Colombia. Por esta razón se realiza esta comunicación con el objetivo de documentar los hallazgos clínicos y anatomopatológicos de un caso de EEI, discutir sus posibles causas, los mecanismos involucrados en su desarrollo y los posibles diagnósticos diferenciales.

Este reporte se realizó para alertar a los médicos veterinarios en Colombia sobre la necesidad de incluir a la EEI en el inventario de enfermedades presentes en los bovinos en nuestro medio.

\section{EVALUACIÓN DE LA PACIENTE}

Anamnésis. En la hacienda "La Montaña" propiedad de la Universidad de Antioquia, ubicada en el municipio de San Pedro de los Milagros en una zona de bosque húmedo montañoso bajo, a una altura entre los 2350 y los 2500 metros sobre el nivel del mar, con una temperatura promedio de $15^{\circ} \mathrm{C}$, se presenta un caso clínico ocurrido en el año 2008, de una vaca Holstein, alimentada con pasto Kikuyo (Pennisetum clandestinum), concentrado, sal y agua a voluntad. Este animal había sido vacunado contra fiebre aftosa, brucelosis, carbón sintomático, septicemia hemorrágica y edema maligno. Se realiza desparasitación de la vaca periódicamente de acuerdo al resultado de los exámenes coprológicos. En la vaca estudiada en los exámenes previos a la necropsia, no se observó carga parasitaria significativa ( $<100$ huevos/gr).

La paciente tenía 8 años de edad, 6 partos previos y una producción de 13 litros leche día. Presentó diarrea crónica intermitente durante seis meses y un carcinoma de células escamosas en vulva, con una evolución aproximada de ocho meses. La diarrea no se trató debido a que se desconocía su etiología y a que el animal mantuvo un adecuado consumo de alimento y una producción acorde con la etapa productiva; el carcinoma no se trató por razones económicas. Quince días previos al deceso la paciente presentó vesículas, pápulas y úlceras en la piel del dorso, ollares y de los pezones que se trataron con ungüentos tópicos a base de antibióticos y cicatrizantes, además, se evidenció sialorrea, secreción nasal mucopurulenta y disnea inspiratoria. Estos últimos síntomas en conjunto se diagnosticaron como una neumonía de tipo bacteriano, que fue tratada con Oxitetraxiclina $11 \mathrm{mg} / \mathrm{kg}$ de peso vivo, durante cuatro días.

Hallazgos al examen clínico. En el momento previo al fallecimiento de la vaca, las alteraciones más importantes encontradas fueron: hiperpnea, disnea inspiratoria y aumento del murmullo vesicular. Se observaron las mucosas congestionadas y pulso yugular positivo. Se evidenció marcado bruxismo y diarrea. En la piel del periné en contacto con la mucosa vaginal se encontró un tumor de forma irregular maloliente, con una amplia base de implantación, no desplazable, de $30 \mathrm{~cm}$ de largo por 15 de ancho con amplias zonas 
de apariencia necrótica entremezcladas con áreas que presentaban secreción purulenta, que sangraban fácilmente al tacto. Esta lesión tumoral poseía un diagnóstico previo de carcinoma de células escamosas efectuado por histopatología, en el Laboratorio de Patología Animal de la Universidad de Antioquia. En la piel del lomo y la ubre se evidenciaron zonas alopécicas, eritematosas, ulceradas con formación de costras; los ollares presentaban úlceras y costras. Se encontró una frecuencia respiratoria por encima del valor de referencia (Tabla 1) y una condición corporal de 2.5 , por debajo del valor de referencia (3.5).

Tabla 1. Constantes fisiológicas de la vaca.

\begin{tabular}{lcc}
\hline \multicolumn{1}{c}{ Parámetro } & Resultado & $\begin{array}{c}\text { Valores de } \\
\text { referencia }\end{array}$ \\
\hline Temperatura corporal $\left({ }^{\circ} \mathrm{C}\right)$ & 38.7 & $38-39.5$ \\
Frecuencia cardiaca (lat/min) & 72 & $60-80$ \\
Frecuencia respiratoria (resp/min) & 42 & $10-30$ \\
Tiempo de llenado capilar (seg) & 2 & 3 \\
Frecuencia ruminal (movimientos) & 1 & 3 en 5 min \\
\hline
\end{tabular}

Por múltiples complicaciones que presentó la vaca, con poca respuesta a los tratamientos empleados, el riesgo potencial para la sanidad del hato y por razones humanitarias se recomendó efectuar eutanasia a la paciente; esta se realizó utilizando sobredosis de acepromacina $(10 \mathrm{mg} /$ $\mathrm{kg}$ ), luego se aplicó una solución de $250 \mathrm{mg}$ de sulfato de magnesio diluido en dos litros de agua tibia por vía intravenosa.

Ayudas diagnósticas. Antes de la eutanasia y con fines académicos y preventivos, se le efectuaron los siguientes análisis de laboratorio: hemograma completo y extendidos de sangre para hemoparásitos, se observó un hematocrito bajo y un porcentaje alto de eosinófilos con relación a los valores de referencia respectivamente (Tabla 2 ). Adicionalmente se realizaron pruebas de química sanguínea, que

Tabla 2. Resultados del hemoleucograma.

\begin{tabular}{llll}
\hline Parámetros & \multicolumn{1}{c}{ Unidades } & Resultados & $\begin{array}{l}\text { Valores de } \\
\text { referencia }\end{array}$ \\
\hline Hematocrito & $\%$ & 26.0 & $30.0-40.0$ \\
Hemoglobina & $\mathrm{g} / \mathrm{dl}$ & 10.1 & $8.0-14.5$ \\
Eritrocitos & $10^{\wedge} 6 / \mu \mathrm{l}$ & 5.85 & $5.40-9.00$ \\
MVC & $\mathrm{fl}$ & 44 & $40-60$ \\
$\mathrm{MCH}$ & $\mathrm{pg}$ & 17.3 & $11.0-17.0$ \\
$\mathrm{MCHC}$ & $\mathrm{g} / \mathrm{dl}$ & 38.9 & $30.0-36.0$ \\
Leucocitos & $10^{\wedge} 3 / \mu \mathrm{l}$ & 2.77 & $2.50-7.50$ \\
Neutrófilos & $\%$ & 41 & $15-45$ \\
Eosinófilos & $\%$ & 12 & $1-12$ \\
Basófilos & $\%$ & 2 & $0-2$ \\
Bandas & $\%$ & & $0-2$ \\
Linfocitos & $\%$ & 43 & $45-75$ \\
Monocitos & $\%$ & 2 & $3-15$ \\
Plaquetas & $10 \wedge 3 / \mu \mathrm{l}$ & 534 & $300-800$ \\
Fibrinógeno & $\mathrm{g} / \mathrm{dl}$ & 0.4 & $0.1-0.6$ \\
Proteínas & $\mathrm{g} / \mathrm{dl}$ & 8 & $6.7-8$ \\
\hline
\end{tabular}

evidenciaron Aspartato Amino Transferasa (AST) y Gamma Glutamil Transferasa (GGT) aumentadas. Indicando una posible lesión a nivel del hepatocito y de los conductos biliares (Tabla 3). En el citoquímico de orina no se evidenciaron alteraciones significativas (Tabla 4). La vaca fue negativa en la prueba intradérmica de la tuberculina.

Tabla 3. Resultados de pruebas de funcionamiento hepático.

\begin{tabular}{cccc}
\hline Parámetro & unidad & Resultados & $\begin{array}{c}\text { Valores de } \\
\text { referencia }\end{array}$ \\
\hline GLU & $\mathrm{mg} / \mathrm{DL}$ & 52 & $44-78$ \\
$\mathrm{AST}$ & $\mathrm{U} / \mathrm{L}$ & 169 & $58-100$ \\
$\mathrm{BUN}$ & $\mathrm{mg} / \mathrm{DL}$ & 14 & $6-22$ \\
$\mathrm{GGT}$ & $\mathrm{U} / \mathrm{L}$ & 259 & $22-64$ \\
$\mathrm{ALB}$ & $\mathrm{g} / \mathrm{DL}$ & 3.0 & $3.05-3.55$ \\
$\mathrm{CK}$ & $\mathrm{U} / \mathrm{L}$ & 199 & $56-1236$ \\
\hline
\end{tabular}

Tabla 4. Resultados del examen citoquímico de orina.

\begin{tabular}{ll}
\hline \multicolumn{1}{c}{ Parámetro } & \multicolumn{1}{c}{ Resultado } \\
\hline Aspecto & Turbio \\
Color & Amarillo \\
$\mathrm{PH}$ & 9.0 \\
Densidad & 1.020 \\
Glucosa & Negativa \\
Proteínas & + \\
Cuerpos cetónicos & negativo \\
Pigmentos biliares & Negativo \\
Urobilinógeno & normal \\
Cristales & Fosfatos amorfos +++ \\
\hline
\end{tabular}

El protocolo de necropsia se realizó con base en el descrito previamente (13). Realizando una observación rigurosa en toda su extensión en busca de parásitos y de lesiones ocasionadas por estos. En todas las porciones del intestino se realizaron raspados de la mucosa para análisis microscópico de protozoarios.

Hallazgos anatomopatológicos. En la necropsia se observó: disminución de la masa muscular y de grasa subcutánea y abdominal, ascitis, hidrotórax, aumento en el tamaño de los linfonodos mesentéricos y del bazo; el intestino delgado en toda su extensión presentó apariencia congestiva generalizada y engrosamiento de la mucosa, en el íleon se evidenciaron múltiples pliegues transversales y depresiones que proporcionaban al tejido una apariencia "cerebriforme" (Figura 1). En la evaluación microscópica del íleon se encontró una enteritis eosinofílica, caracterizada por necrosis epitelial multifocal, atrofia y fusión de vellosidades, atrofia de las glándulas intestinales y exocitosis eosinofílica en el epitelio de las vellosidades y en el de las glándulas intestinales. En la lámina propia se evidenció un severo infiltrado leucocitario difuso, predominantemente eosinofílico más acentuado en el tejido conectivo 


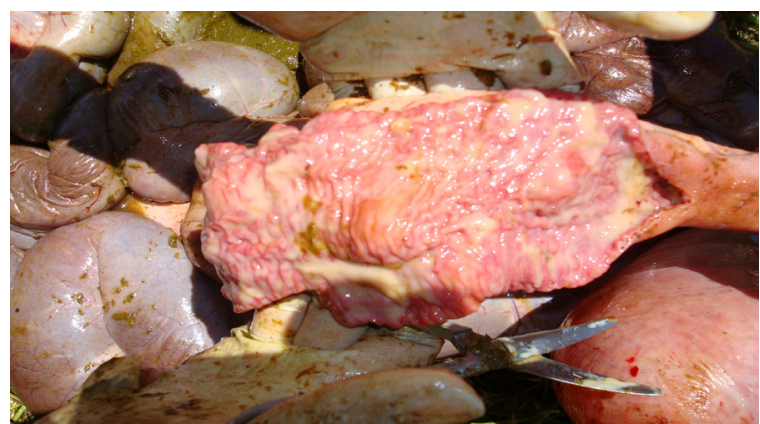

Figura 1. Íleon que presenta engrosamiento de la mucosa y formación de pliegues transversales.

de la vellosidad. También se halló congestión vascular y linfangiectasia moderadas (Figura $2 \mathrm{~A}$ y 2B, Tabla 5). La coloración Azul de Toluidina reveló la presencia de algunos mastocitos. Con la coloración Ziehl-Neelsen (ZN) no se observaron microorganismos ácido alcohol resistentes (Figura 3A), se realizó un control positivo para esta coloración en tejido intestinal

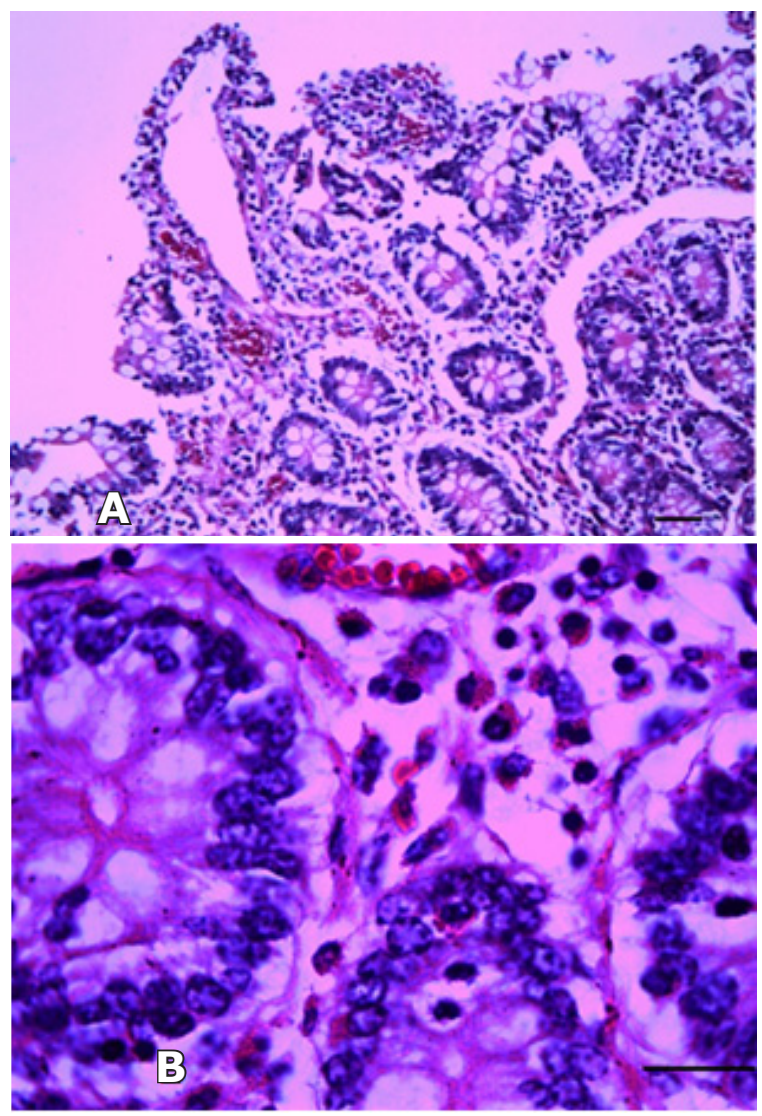

Figura 2. A Mucosa del íleon, presenta descamación epitelial, necrosis, congestión vascular y linfangiectasia en la lámina propia de las vellosidades. H-E. Barra $=60$ micrómetros. B Mucosa de íleon, muestra abundantes eosinófilos que infiltran el intersticio y el epitelio de las glándulas. H-E. Barra = 30 micrómetros. obtenido de otra vaca, a la que previamente se la había diagnosticado Paratuberculosis en el mismo laboratorio (Figura 3B).
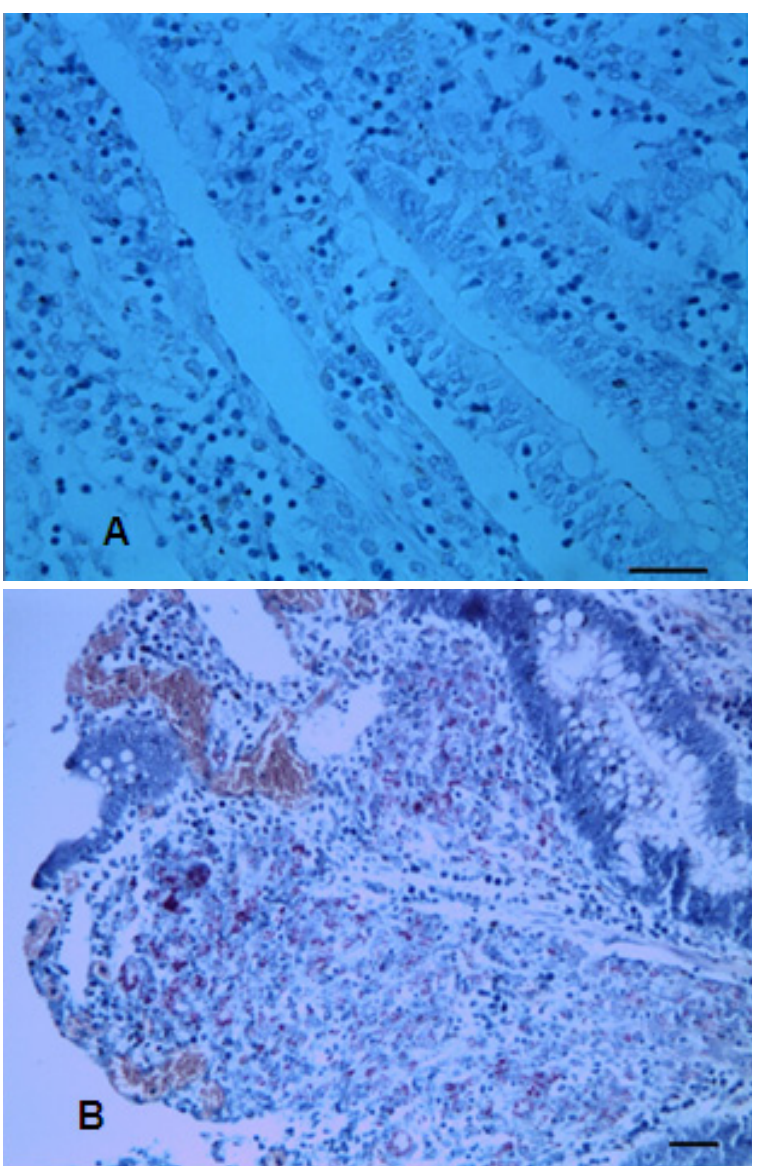

Figura 3. A Mucosa del íleon, EEI negativo para microorganismos ácido alcohol resistentes. Ziehl-Neelsen (ZN). Barra $=50$ micrómetros. B Mucosa intestinal, control positivo para Paratuberculosis, bacilos acido alcohol resistentes. ZN. Barra $=50$ micrómetros.

Otros hallazgos. En varios linfonodos mesentéricos se encontró por histopatología un linfoma de células pequeñas no clivadas (Figura 4) En otros linfonodos del mismo animal se observó fibrosis moderada y presencia de eosinófilos infiltrando discreta y difusamente el tejido. Adicionalmente en la piel del periné y en intima relación con la vulva se halló una masa tumoral que a la reevaluación microscópica correspondió a un carcinoma de células escamosas (Figura 5A).

Enfoque de tratamiento. Los tratamientos utilizados en la paciente fueron basados en su sintomatología, sin respuesta favorable. La vaca se trató con oxitetraciclina y ungüentos tópicos. Para la EEI no se hizo ningún tratamiento, ya que esta solo se diagnóstico 

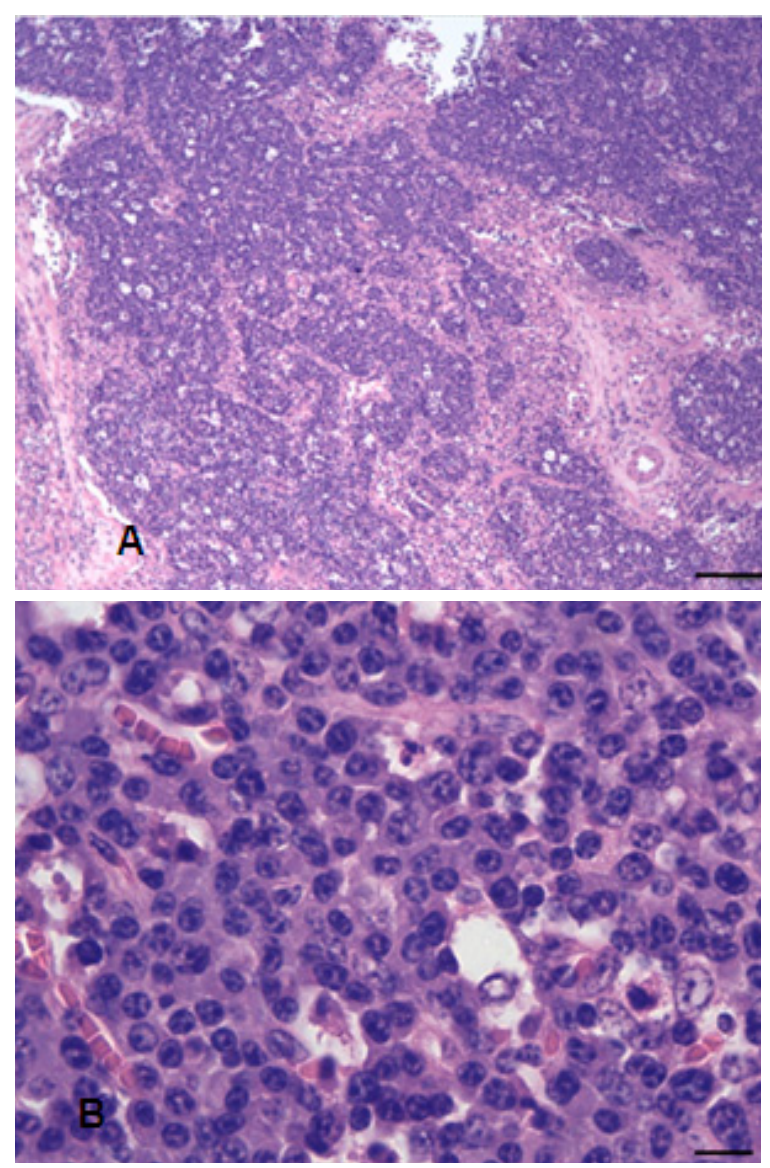

Figura 4. A ganglio linfático mesentérico. Linfoma de células pequeñas no clivadas, presenta una población de linfocitos intercalados con grandes macrófagos que le da la apariencia de "cielo estrellado". HE. Barra $=100$ micrómetros. B células linfoides con núcleo redondo, no clivado y hasta 5 nucléolos. Barra $=10$ micrómetros.

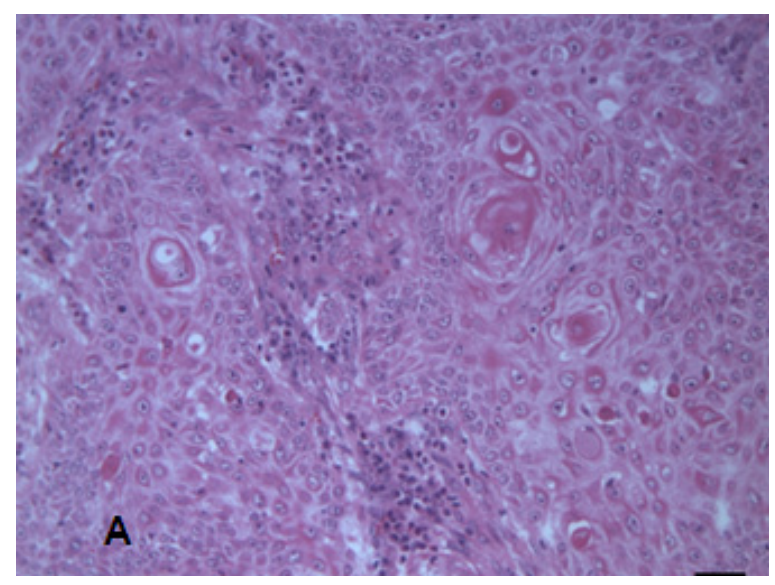

Figura 5. A Piel. Carcinoma de células escamosas, células espinosas bien diferenciadas, con disqueratosis, acompañadas eosinófilos y neutrófilos. HE. Barra $=60$ micrómetros. por histopatología después de la necropsia. El tratamiento para la EEI que se recomienda en bovinos es prednisolona $1.1 \mathrm{mg} / \mathrm{kg}$ subcutáneo durante tres semanas, a la cuarta semana se disminuye gradualmente la dosis; con este tratamiento se ha demostrado supresión de la diarrea y ganancia de peso del animal (8). Por lo tanto la respuesta favorable al tratamiento con corticoides se puede considerar como una ayuda diagnóstica en bovinos con diarrea crónica y pérdida de peso, en los cuales se tenga una presunción diagnóstica de EEI (1).

\section{DISCUSIÓN}

En esta comunicación se reporta un caso de una vaca que presentaba diarrea, enflaquecimiento y lesiones macroscópicas en intestino delgado que correspondieron histológicamente a EEI.

La EEI bovina es una enfermedad, aceptada por algunos autores como una condición nosológica que causa diarrea crónica y pérdida de peso en bovinos adultos (1). Esta enfermedad también se ha documentado en varias especies. Su diagnóstico en todas las especies se realiza con base en la combinación de la evaluación clínica, la evaluación histopatológica y por la exclusión de otras enfermedades (3). Varios autores consideran que el diagnóstico confirmatorio debe realizarse mediante la evaluación histopatológica del intestino delgado para verificar la existencia de un proceso inflamatorio con un infiltrado leucocitario en el que predominen los eosinófilos (10).

La historia clínica y el examen físico, revelaron una enfermedad diarreica, de curso crónico, con pérdida importante en el peso corporal, estos hallazgos son similares a los reportados por otros autores en casos diagnosticados de EEI en diferentes especies animales $(8,10)$.

En la evaluación macroscópica post mortem del intestino delgado se encontró engrosamiento severo de la mucosa, lo que concuerda con la lesión comunicada en humanos y en equinos que padecieron de EEI (14); sin embargo, cuando esta alteración está acompañada en los bovinos por pliegues y surcos como se observó en estos casos, se asocia comúnmente a Paratuberculosis (15) y a enteritis por Prototheca sp (7). En estas enfermedades el engrosamiento de la mucosa observado macroscópicamente, se debe al aumento de un infiltrado celular inflamatorio, difuso en la lámina propia. Por lo expuesto anteriormente se concluye que aunque el hallazgo de esta lesión ayuda en la orientación del diagnóstico, no se debe considerar confiable 
para emitir un diagnóstico definitivo, por lo que siempre se debe recurrir al examen histopatológico confirmatorio $(3,12)$.

En general el intestino tiene un limitado número de formas de reacción inflamatoria, que se han clasificado según la lesión predominante o el tipo de reacción a saber enteritis: catarral, hemorrágica, fibrinosa, ulcerosa y proliferativa (16). Debido a que las alteraciones histológicas en estos casos no pudieron ubicarse en una de las anteriores clasificaciones, se emitió un diagnóstico de enteritis eosinofílica, basándose en la histopatología anotada previamente por varios autores como: presencia de alteraciones inflamatorias en el intestino e infiltración abundante de eosinófilos principalmente dentro de las vellosidades y en las criptas intestinales, (4, 12). En el íleon de la vaca estudiada se confirmaron alteraciones histopatológicas asociadas a enteritis, como atrofia y fusión de vellosidades, necrosis y erosión epitelial, atrofia de algunas glándulas intestinales e hiperplasia de otras, se observó un infiltrado de abundantes eosinófilos en la lámina propia. Estos hallazgos concuerdan con los criterios histológicos propuestos para identificar la EEI $(1,3)$.

Otras lesiones histológicas que comúnmente se han encontrado en esta condición son linfangiectasia y congestión vascular; estas alteraciones también fueron observadas en la paciente evaluadas. Además, se presentó infiltración discreta difusa de eosinófilos en los linfonodos mesentéricos y eosinofília en el carcinoma de células escamosas y en sangre. En los humanos se ha reportado que existen tres formas de enteritis eosinofílica (EE), una forma mucosa, en la cual se compromete únicamente la mucosa, esta es la variedad más común; una forma muscular que se caracteriza por infiltración de la muscular con síntomas de obstrucción o estenosis y una forma serosa que es la menos común y presenta ascitis y eosinofília periférica (3). Aunque la vaca presentó ascitis y mostró eosinófilos en el rango superior del leucograma, no tuvo un infiltrado eosinofílico significativo en la serosa. La infiltración eosinofílica también puede afectar múltiples órganos y producir una entidad conocida como síndrome hiperosinofílico, que ha sido identificado en varias especies (17). Los hallazgos de la vaca sugieren una forma sistémica de la enfermedad.

No se halló evidencia de endoparasitismo en la evaluación macroscópica, en los cortes histológicos, ni en los raspados realizados de las diferentes porciones del intestino delgado o grueso. De lo anterior se concluye que aunque no se evidenció la presencia de parásitos en las muestras evaluadas, no es posible descartar completamente su presencia en el tubo digestivo.

En la química sanguínea se encontró aumento de la enzima AST indicando una posible lesión a nivel del hepatocito; adicionalmente se encontró aumento de la GGT probablemente relacionada con alteración de los conductos biliares (Tabla 3). Esta presunción se confirmó ya que se identificó Fasciola sp. causando colangiohepatitis; esta lesión se ubicó en el espacio porta y se caracterizó por infiltración linfoplasmocitaria, sin eosinófilos; de esto se deduce que es poco probable que estos parásitos hayan causado la EE. Este argumento se apoya en las observaciones de otros autores, quienes informan que usualmente no hay reacción inflamatoria evidente causada por el paso de las Fasciolas a través de la pared intestinal (2).

En la evaluación del íleon se observaron alteraciones macroscópicas compatibles con Paratuberculosis; sin embargo, su valoración histopatológica no reveló la presencia de granulomas, ni de bacilos ácido alcohol resistentes, son los hallazgos histológicos característicos asociados a lesiones macroscópicas bien desarrolladas de esta enfermedad. Se ha comunicado que bovinos positivos a Mycobacterium avium paratuberculosis (MAP), que presentan alteraciones macroscópicas mínimas o ausentes en intestino, pueden presentar alteraciones microscópicas más sutiles; en dichos casos la lámina propia tiene un infiltrado difuso de linfocitos, plasmocitos, abundantes eosinófilos y escasos macrófagos (2). Es importante resaltar que la vaca estudiada presentó alteraciones macroscópicas severas, que de ser debidas a MAP deberían presentar una reacción granulomatosa evidente y no los cambios sutiles asociados generalmente a las formas leves de esta enfermedad (12). En un estudio en el que se indagó por la asociación de la severidad de la inflamación granulomatosa intestinal con la infección por MAP, se encontró una vaca a la que se le diagnosticó EE severa, en esta vaca no se logró cultivar el MAP, ni mostró seropositividad en la prueba de ELISA. Esto sugiere que en esa situación particular la EE fue una condición independiente de la Paratuberculosis (12). Es probable que algo similar ocurra en el caso reportado aquí.

Debido a la imposibilidad de explicar la infiltración intestinal de eosinófilos en el caso como consecuencia de parasitismo, infección por micobacterias, por hongos o por algas, y a 
que no se pudo establecer otra causa específica, para este tipo de inflamación, se acuñó el término idiopático al diagnóstico de $\operatorname{EE}(14,4)$.

La causa de la EEI usualmente es desconocida, pero puede asociarse con reacción inmune, hipersensibilidad en respuesta a migración larvaria de parásitos, Pythium sp en equinos, hongos, cuerpos extraños como material de plantas, y alergias alimentarias (10). En humanos medicamentos como azathioprine, enalapril, gemfibrozil, trimetroprim sulfa (18) y patologías como lupus eritomatoso sistémico también han sido implicadas (11). En este estudio no se logró identificar ningún agente infeccioso relacionado con las lesiones, tampoco se encontró evidencia en la historia clínica de la utilización de alguno de los medicamentos antes citados; no obstante, en la evaluación microscópica del íleon, con la coloración Azul de Toluidina se evidenció presencia discreta de mastocitos de manera similar a lo comunicado anteriormente en caninos (19). Se ha propuesto que el incremento de mastocitos y eosinófilos en la mucosa intestinal con gastroenteritis eosinofílica de humanos y caninos podría indicar la presencia de una reacción de hipersensibilidad tipo 1 como respuesta a antígenos de la dieta (20). Debido a que esta hipótesis no se pudo demostrar en este caso, se deben realizar otros estudios en la población bovina para identificar casos adicionales y realizar una investigación sistemática que caracterice el problema.

Otro mecanismo probablemente involucrado en la presentación de la EE en la vaca es la presencia de un síndrome paraneoplásico. Se ha informado que diferentes neoplasias cursan con eosinofília paraneoplásica (21). Estudios recientes revelaron que la eosinofília puede ser inducida por factores eosinofilopoyéticos asociados a cáncer, entre los que se incluyen citoquinas que cumplen un papel importante en el desarrollo, diferenciación y quimiotaxis de los eosinófilos (22). Entre estas citoquinas se encuentran el Factor Estimulante de Colonias Granulocito - Macrófago (GM- CSF por sus siglas en Inglés), Interleuquina 3 (IL- 3 ) e Interleuquina 5 (IL-5) (3).

La vaca presentó neoplasias, como un linfoma de células pequeñas no clivadas y un carcinoma de células escamosas (Tabla 5). En humanos se ha reportado un carcinoma de células escamosas asociado con eosinofilia y con un nivel elevado de IL-5 sérico, molécula quimiotáctica para eosinófilos (23). También existen reportes que sugieren que un linfoma de células $T$, secretor de interleuquina 5 , puede ser el responsable de este tipo de enteritis en algunos pacientes equinos y en gatos $(22,14)$. Las neoplasias de células $B$ en humanos pueden producir Factor de Necrosis Tumoral alfa (TNFa por sus siglas en Inglés) e IL-13, estimulando de este modo la secreción de eotaxina por los fibroblastos, molécula quimiotáctica para eosinófilos (24). La ausencia de otras causas de eosinofília tisular en el caso reportado aquí, y la presencia de dos neoplasias en la vaca sugieren que la eosinofília paraneoplásica podría ser el principal mecanismo asociado a las alteraciones encontradas en su intestino.

En este estudio se evidenciaron alteraciones (Tabla 5), en diferentes órganos aparentemente inconexas; no obstante, este cuadro multiorgánico podría estar asociado a inmunosupresión. Este efecto pudo ser el resultado de las lesiones neoplásicas en la paciente, con la consecuente inducción de síndrome paraneoplásico, incremento de eosinófilos, daño tisular por aumento de proteínas granulares tóxicas y liberación de sustancias tóxicas a la circulación general (9). Es importante señalar que el linfoma bovino se asocia comúnmente con el virus (BLV) que produce la leucosis bovina. Esta enfermedad puede causar alteraciones multisistémicas asociadas con su efecto inmunosupresor (2).

En conclusión, en este estudio se documenta el caso de una vaca que presentó inflamación intestinal diagnosticada como EEI, con base en el análisis de los hallazgos clínicos, histopatológicos y la exclusión de la presencia de otras enfermedades. Las causas de esta enfermedad se desconocen, sin embargo, debido a que no se identificaron agentes infecciosos en el caso y a la presencia de neoplasias, se postula como mecanismo más probable de enfermedad, el síndrome denominado hipereosinofilia paraneoplásica (21). Otro mecanismo causal que no se debe excluir en este caso es alergia primaria; esta causa se debe sospechar en pacientes que presenten síntomas de alteración gastrointestinal y eosinofília periférica, cuando la evaluación clínica convencional no permita emitir una explicación satisfactoria (3). El examen histopatológico es esencial para realizar el diagnóstico debido a que las lesiones macroscópicas no son específicas, por lo que esta condición puede ser no reconocida por médicos veterinarios que no están familiarizados con las lesiones.

El caso expuesto en este reporte, es el único comunicado hasta donde se conoce de EEI bovina en Colombia, y uno de los pocos en el mundo. Se requiere realizar investigaciones epidemiológicas de esta enfermedad para identificar los factores de riesgo asociados y estudios de patogenia para esclarecer sus causas. 


\section{REFERENCIAS}

1. Divers TJ, Peek SF. Rebhun's diseases of dairy cattle. Saunders W.B. 2nd ed. USA: Elsevier Health Sciences; 2008.

2. Maxie MG, Jubb KVF, Kennedy PC, Palmer N. Pathology of domestic animals. vol 2 5th ed. USA: Saunders; 2007.

3. Baig MA, Qadir A, Rasheed J. A review of eosinophilic gastroenteritis. J Nati Med Assoc 2006; 98:1616-1619.

4. Archer DC, Barrie EG, Kelly DF, French NP, Proudman $\mathrm{CJ}$. Obstruction of equine small intestine associated with focal idiopathic eosinophilic enteritis: an emerging disease? Vet J 2006; 171(3):504-512.

5. Kheirandish R, Khodakaram AT, Hosseini A. The comparative evaluation of immunohistochemical and acid fast staining with histopathological changes in naturally occurring paratuberculosis in sheep. Comp Clin Pathol 2008; 17:111-116.

6. Gozalo AS, Rosenberg HF, Elkins WR, Montoya EJ, Weller RE. Multisystemic eosinophilia resembling hypereosinophilic syndrome in a colony-bred owl monkey (Aotus vociferans). J Am Assoc Lab Anim Sci 2009; 48(3):303-6.

7. Osterstock JB, Manssel JL, Roussel AJ. Protothecal enteritis as a cause of proteinlosing enteropathy in a bull. J Am Vet Assoc 2005; 227(9):1476-9.

8. Belknap EB, Navarre CB. Differentiation of gastrointestinal diseases in adult cattle. Vet Clin North Am Food Anim Pract 2000 16(1): 59-86.

9. Hogan SP. Functional Role of Eosinophils in Gastrointestinal Inflammation. Immunol Allergy Clin N Am 2009; 29:129-140.

10. Southwood LL, Kawcak CE, Trotter GW, Stashak TS, Frisbie DD. Idiopathic focal eosinophilic enteritis associated with small intestinal obstruction in 6 horses. Vet surg $2000 ; 29: 415-419$.

11. Zuo Li, Rothenberg ME. Gastrointestinal Eosinophilia. Immunol Allergy Clin $\mathrm{N}$ Am 2007; 27: 443-455.
12. Dennis MM, Antognoli MC, Garry FB, Hirst HL, Lombard JE, Gould D, Salman MD. Association of severity of enteric granulomatous inflammation with disseminated Mycobacterium avium subspecies paratuberculosis infection and antemortem test results for paratuberculosis in dairy cows. Vet Microbiol 2008; 131: 154-163.

13. Aluja AS, Casas FC. Técnicas de necropsia en animales domésticos. 2a ed. México; Manual moderno; 2002 p.103.

14. Schumacher J, Edwards JF, Cohen N. Review Chronic idiopathic inflammatory bowel diseases of the horse. J Vet Intern Med 2000;14: 254-265.

15. Khare S, Ficht $T A$, Santos RL, Romano J, Ficht AR, Zhang S, et al. Rapid and sensitive detection of Mycobacterium avium subsp. paratuberculosis in bovine milk and feces by a combination of Immunomagnetic Bead Separation-Conventional PCR and Real-Time. J Clin Microbiol 2004; 42:1075-1081.

16. Trigo FJ, Valero EG. Patología General Veterinaria. 4a ed. Mexico: Universidad Nacional Autónoma de México; 2004.

17. German AJ, Holden DJ, Hall EJ, Day MJ. Eosinophilic diseases in two Cavalier King Charles Spaniels. J Small Anim Pract 2002, 43(12):533-538.

18. Morimoto $T$, Sato $T$, Matsuoka A, Sakamoto $\mathrm{T}$, Ohta K, Ando $\mathrm{T}$ et al. Trimethoprimsulfamethoxazole-induced hypersensitivity syndrome associated with reactivation of human herpesvirus-6. Intern Med 2006; 45(2):101-105.

19. Kleinschmidt $S$, Meneses $F$, Nolte I, Hewicker-T M. Characterization of mast cell numbers and subtypes in biopsies from the gastrointestinal tract of dogs with lymphocytic-plasmacytic or eosinophilic gastroenterocolitis. Vet Immunol Immunopathol 2007; 120(3-4):80-92.

20. Dehlink E, Fiebiger E. The Role of the HighAffinity IgE Receptor, FCERI, in Eosinophilic Gastrointestinal Diseases. Immunol Allergy Clin N Am 2009; 29: 159-170. 
21. Barrs VR, Beatty JA, McCandlish IA, Kipar A. Hypereosinophilic paraneoplastic syndrome in a cat with intestinal $T$ cell lymphosarcoma. J of Small Anim Pract 2006; 43 ( 9): 401-405.

22. Cave TA, Gault EA, Argyle DJ. Feline epitheliotrophic T-cell Iymphoma with paraneoplastic eosinophilia immunochemotherapy with vinblastine and human recombinant interferon $a 2 b$. Vet Comp Oncol 2004; 2(2):91-7.
23. Walter R, Joller-J HI, Salomon F. Metastatic squamous cell carcinoma with marked blood eosinophilia and elevated serum interleukin-5 levels. Exp Hematol 2002, $30(1): 1-2$.

24. Poppema, S. Van Den Berg, A. Interaction between host $T$ cells and Reed Sternberg cells in Hodgkin lymphomas. Semin Cancer Biol 2000;10(5):345-50. 